\title{
EFFECT OF SUBSTRATE CONCENTRATION ON THE BIOTRANSFORMATION OF CARBON TETRACHLORIDE AND 1,1,1-TRICHLOROETHANE UNDER ANAEROBIC CONDITION
}

\author{
RUEY-AN DOONG ${ }^{1 *}$ and SHIAN-CHEE WU ${ }^{2} \otimes$ \\ 'Department of Nuclear Science, National Tsing Hua University, Hsinchu, Taiwan 30043 and \\ ${ }^{2} 71$ Chou-Shan Rd, Graduate Institute of Environmental Engineering, National Taiwan University, \\ Taipei, Taiwan 10670, Republic of China
}

(First received March 1994; accepted in revised form August 1995)

\begin{abstract}
The biotransformabilities of 1,1,1-trichloroethane (TCA) and carbon tetrachloride (CT) were investigated at $35^{\circ} \mathrm{C}$ under low concentration of acetic acid as the auxiliary substrate to evaluate the concentration effect of the auxiliary substrate on the biotransformation of the chlorinated hydrocarbons. Data shown in this study demonstrated that concentration of acetic acid could change the dechlorination capability of the microorganisms and, thus, influence the biotransformation of chlorinated hydrocarbons. The rate of the biotransformation of CT and TCA in the concentration range of $100-1000 \mu \mathrm{g} / 1$ increased progressively with the increase of the substrate concentration ranged from 0 to $30 \mathrm{mg} / \mathrm{l}$. Nearly complete biotransformation of CT was obtained in 32 days. TCA was degraded slower than CT and removal of $20-91 \%$ was observed in 85 days, depending on the concentrations of both the primary substrate and the chlorinated compound. These removal efficiencies corresponded to second-order rate coefficients of $0.0006-0.0041 \mathrm{l} / \mathrm{mg}-\mathrm{VSS} / \mathrm{d}$ and $2.75 \times 10^{-5}$ to $2.97 \times 10^{-4} \mathrm{l} / \mathrm{mg}-\mathrm{VSS} / \mathrm{d}$ for CT and TCA, respectively. Available substrate supply is essential for the dechlorination of chlorinated compounds which is demonstrated by the experimental results showing the effects of the substrate concentration and the compound concentration. Also, the difference between the oxidation-reduction potentials of these two chlorinated hydrocarbons gives a possible explanation for the difference of the biotransformabilities of CT and TCA under some substrate conditions.
\end{abstract}

Key words-chlorinated hydrocarbons, carbon tetrachloride, 1,1,1-trichloroethane, auxiliary substrate, biotransformation, second-order rate coefficient, reductive dechlorination

\section{INTRODUCTION}

The contamination of groundwater by a variety of organic substances becomes a great concern in recent years. Because of their suspected carcinogenicity and their ubiquity in groundwater, the behavior of the low-molecular-weight chlorinated hydrocarbons in groundwater is currently the subject of many researches.

Biological transformation is the main attenuation mechanism for the chlorinated hydrocarbons in the natural ecosystems. Recent investigations have repeatedly shown that the chlorinated hydrocarbons can be cometabolized by methanothrophs in the presence of air and methane (Semprini and McCarty, 1992; Hopkins et al., 1993; Enzien et al., 1994). However, some heavily chlorinated compounds such as carbon tetrachloride (CT) and 1,1,1trichloroethane (TCA) are highly resistant to the aerobic microbial consortia and subjected to the

*Author to whom all correspondence should be addressed [Tel.: (886) 35 726785; Fax.: (886) 35 718649]. reductive dechlorination under reducing environments (Thomas and Ward, 1989).

Reductive dechlorination of chlorinated hydrocarbons has been observed in both natural and laboratory reducing environments (DiStefano et al., 1991; Gibson and Sewell, 1992; Semprini et al., 1992; Doong and $\mathrm{Wu}, 1995)$. The reductive dechlorination requires an electron donor produced by a transfer of electron from an organic substrate to chlorinated hydrocarbons and the addition of external carbon and energy sources is necessary for the dechlorination of chlorinated hydrocarbons. Several researches have demonstrated the effects of the types of supplemented substrates, such as acetate, glucose, lactate, and methanol, on the biotransformation of polychlorinated biphenyls (PCBs) (Nies and Vogel, 1990); tetrachloroethylene (PCE) (Fathepure and Boyd, 1988; Bagley and Gossett, 1990), 2,4,5-T (Gibson and Suflita, 1990) and chloroanilines (Kuhn et al., 1990). Nevertheless, investigations concerning the substrate concentration effect on the biotransformation of chlorinated compounds are limited. 
Table 1. Composition of the anaerobic medium used in the experiments

\begin{tabular}{lclc}
\hline Compounds & $\begin{array}{c}\text { Concentration } \\
(\mathrm{mg} / \mathrm{l})\end{array}$ & \multicolumn{1}{c}{ Compounds } & $\begin{array}{c}\text { Concentration } \\
(\mathrm{mg} / \mathrm{l})\end{array}$ \\
\hline $\mathrm{MgCl}_{2} \cdot 6 \mathrm{H}_{2} \mathrm{O}$ & 1800 & $\mathrm{KCl}$ & 1300 \\
$\left(\mathrm{NH}_{4}\right)_{2} \mathrm{HPO}_{4}$ & 500 & $\mathrm{CaCl}_{2} \cdot 2 \mathrm{H}_{2} \mathrm{O}$ & 250 \\
$\mathrm{NH}_{2} \mathrm{Cl}$ & 400 & $\mathrm{Na}_{2} \mathrm{~S} \cdot 9 \mathrm{H}_{2} \mathrm{O}$ & 500 \\
$\mathrm{FeCl}_{2} \cdot 4 \mathrm{H}_{2} \mathrm{O}$ & 370 & & \\
$\mathrm{Trace} \mathrm{elements}_{\mathrm{MnCl}_{2} \cdot 4 \mathrm{H}_{2} \mathrm{O}}$ & 20 & $\mathrm{CoCl}_{2} \cdot 6 \mathrm{H}_{2} \mathrm{O}$ & 30 \\
$\mathrm{CuCl}_{2} \cdot 2 \mathrm{H}_{2} \mathrm{O}$ & 2.7 & $\mathrm{ZnCl}_{2}$ & 2.1 \\
$\mathrm{H}_{3} \mathrm{BO}_{3}$ & 5.7 & $\mathrm{Na}_{2} \mathrm{MoO}_{4} \mathrm{Cl}_{2} \cdot 2 \mathrm{H}_{2} \mathrm{O}$ & 2.6 \\
Vitamins & & & \\
Biotin & 0.02 & Folic acid & 0.02 \\
Riboflavin & 0.05 & Thiamin & 0.05 \\
Nicotinic acid & 0.05 & Pantothenic acid & 0.05 \\
B & 0.001 & $p$-aminobenzoic acid & 0.05 \\
Thioctic acid & 0.05 & & \\
\hline
\end{tabular}

In-situ bioremediation is a progressive technology for the remediation of groundwater contaminated with chlorinated hydrocarbons in the respect of cost and effectiveness. Among the 31 halogenated hydrocarbons in the 129 priority pollutants promulgated by U.S. EPA, CT and TCA are widely used as solvents and degreasing agents for domestic and industrial purposes and are currently listed as volatile organic contaminants under the Safe Drinking Act amendments of the United States (Federal Register, 1989), with proposed maximum contaminant level in drinking water of 5 and $200 \mu \mathrm{g} / \mathrm{l}$, respectively. In this study the biotransformabilities of CT and TCA with acetic acid as the auxiliary substrate were investigated to evaluate the concentration effect of the supplemental organic substrate on the biotransformation of chlorinated hydrocarbons. The experiments concerning the concentration effect of CT and TCA were also performed to examine the behavior of these two different compounds under different initial concentrations. In addition, kinetic aspect of the biotransformation of CT and TCA were also discussed and a biodegradation model was proposed for predicting the change of the chlorinated hydrocarbon concentration in different environmental conditions.

\section{MATERIALS AND METHODS}

\section{Reagents and materials}

The chlorinated hydrocarbons used in this study, carbon tetrachloride (CT) $(99.8 \%+), \quad$ GC grade, $1,1,1$. trichloroethane (TCA) $(99.8 \%+)$, GC grade, and chloroform (CF) $(99.8 \%+)$, GC grade were purchased from Merck Co., Darmstadt, Germany. Acetic acid $(99.8 \%+)$, biochemical grade, was obtained from Janssen Co., Belgium.

Anaerobic mix-culture consortia was obtained from the anaerobic digester of the Taiwan Sugar Co. wastewater treatment facility (Hsinchu, Taiwan). It was then incubated at $35^{\circ} \mathrm{C}$ in a $21^{\circ}$ glass flask with magnetic stirrer under anaerobic condition. $200 \mathrm{ml}$ of the substrate solution consisting of acetic acid $(15,000 \mathrm{mg} / \mathrm{l})$, propionic acid $(5000 \mathrm{mg} / \mathrm{l})$, vitamins, reducing agents $\left(\mathrm{Na}_{2} \mathrm{~S} ; \mathrm{FeCl}_{2}\right)$, and mineral growth factors were added into the inoculum culture daily to keep adequate microbial activities. The supplement of substrate solution was stopped 2-3 d before the beginning of each experiment in order to exhaust the residual carbon sources in the anaerobic culture. Some characteristics of the inoculating solution were: total organic carbon (TOC) of the supernatant, $24.2 \mathrm{mg}-\mathrm{C} / 1$; volatile suspended solid (VSS) (decomposable at $550^{\circ} \mathrm{C}$ ) concentration, $5562 \mathrm{mg}-\mathrm{VSS} / \mathrm{l}$; and the ratio of VSS to the total suspended solid was about 0.56 .

\section{Biotransformation experiments}

Experiments were conducted in a batch-fed mode. Sterilized $60 \mathrm{ml}$ serum bottles were filled with $45 \mathrm{ml}$ of the reducing media with the composition listed in Table 1 . An aliquot of the inoculating solution $(1 \mathrm{ml})$ was introduced into each bottle, which was then purged with nitrogen gas and sealed with Teflon-lined rubber septum and an aluminum crimp cap (The Wheaton Co., N.J.). The chlorinated compounds and the auxiliary organic substrate were delivered into serum bottle by diluting the stock solutions $(125 \mathrm{mg} / \mathrm{l}$ for chlorinated hydrocarbons and $750 \mathrm{mg} / 1$ for auxiliary substrate) to obtain liquid concentrations of 100 , 500 , or $1000 \mu \mathrm{g} / 1$ for chlorinated compounds and $0,5,10$, 20 , or $30 \mathrm{mg} / \mathrm{l}$ for auxiliary substrate, respectively. The total volume of the liquid phase was $50 \mathrm{ml}$, and a $10-\mathrm{ml}$ headspace was left for headspace analysis.

Stock solutions of chlorinated compounds and acetic acid were prepared in aqueous form, with the concentrations of the chlorinated compounds below their water solubilities at room temperature. In addition, all reagents were prepared with deionized distilled waters purified with Milli-Q reagent water system (Millipore Co., Bedford, Mass.). All glasswares were cleaned with cleaning solution, rinsed with deionized distilled water, methanol, acetone, and hexane in sequence, dried at $105^{\circ} \mathrm{C}$ and sealed with clean aluminum foil before use.

Blank controls were performed by following the procedures described above except the seeding with bacterial culture, and $10 \mathrm{mg} / \mathrm{l}$ of $\mathrm{HgCl}_{2}$ were added as microbial inhibitors. All serum bottles were wrapped in aluminum foil to avoid photodecomposition and incubated at $35^{\circ} \mathrm{C}$.

\section{Abiotic transformation}

Four types of media, F, S, FS, and BL, containing different reducing agents listed in Table 2 were used as

Table 2. The types and concentrations of reducing agents in media used in the abiotic transformation experiment

\begin{tabular}{lll}
\hline Medium $^{\mathrm{a}}$ & $\begin{array}{c}\text { Reducing } \\
\text { agent }\end{array}$ & $\begin{array}{c}\text { Concentration } \\
(\mathrm{mg} / \mathrm{l})\end{array}$ \\
\hline F medium & $\mathrm{FeCl}_{2} \cdot 4 \mathrm{H}_{2} \mathrm{O}$ & $370(1.85 \mathrm{mM})$ \\
& $\mathrm{Na}_{2} \mathrm{SO}_{3}$ & $260(2.06 \mathrm{mM})$ \\
S medium & $\mathrm{Na}_{2} \mathrm{~S} \cdot 9 \mathrm{H}_{2} \mathrm{O}$ & $500(2.06 \mathrm{mM})$ \\
Fs medium & $\mathrm{FeCl}_{2} \cdot 4 \mathrm{H}_{2} \mathrm{O}$ & $370(1.85 \mathrm{mM})$ \\
& $\mathrm{Na}_{2} \mathrm{~S} \cdot 9 \mathrm{H}_{2} \mathrm{O}$ & $500(2.06 \mathrm{mM})$ \\
BL medium & $\mathrm{Na}_{2} \mathrm{SO}_{3}$ & $260(2.06 \mathrm{mM})$ \\
\hline
\end{tabular}

${ }^{\mathrm{a}} \mathrm{F}$ medium: solution containing ferrous ion ( $\mathrm{Fe}^{2+}$ ) alone.

$S$ medium: solution containing sulfide ion $\left(\mathrm{S}^{2-}\right)$ alone.

FS medium: solution containing ferrous and sulfide ions BL medium: blank control. 


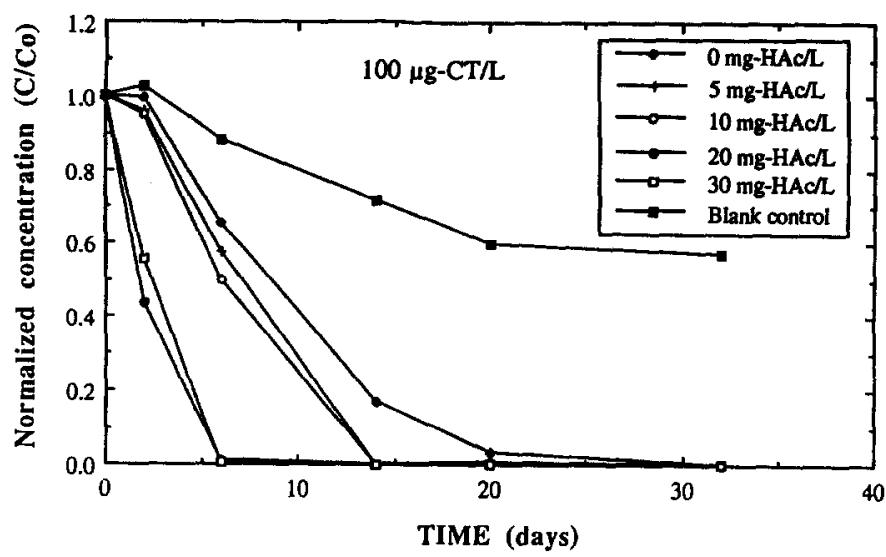

Fig. 1. Biotransformation of $100 \mu \mathrm{g} / 1$ of carbon tetrachloride (CT) with the supplement of auxiliary substrate (acetic acid) ranged from 0 to $30 \mathrm{mg} / \mathrm{l}$.

reducing agents. Resazurin was added in each medium as a redox indicator. All media except reducing agents were autoclaved after preparation and allowed to cool to room temperature. $8.4 \mathrm{~g}$ of $\mathrm{NaHCO}_{3}(0.1 \mathrm{M})$ was added into each medium, bubbled with $\mathrm{CO}_{2}$ gas to adjust $\mathrm{pH}$ to 7.0.

Each sterile $60 \mathrm{ml}$ serum bottle was filled with $45 \mathrm{ml}$ of the appropriate medium (F, S, FS, or BL medium) for the designed purpose. Stock solutions of chlorinated hydrocarbons, which were dissolved in methanol at the concentration of $250 \mathrm{mg} / \mathrm{ml}-\mathrm{MeOH}$, were introduced into each bottle to give the final liquid concentrations of $100 \mu \mathrm{g} / \mathrm{l}$. In addition, all media were supplemented with $10 \mathrm{mg} / 1$ of $\mathrm{HgCl}_{2}$ to inhibit the microbial growth. Bottles were subsequently sealed with Teflon-lined silicon septa and aluminum crimp caps, wrapped in aluminum foil to avoid photodecomposition, and incubated at $35^{\circ} \mathrm{C}$. The total volume of the liquid phase was $50 \mathrm{ml}$, and a $10-\mathrm{ml}$ gas phase was left for headspace analysis.

\section{Analytic methods}

The concentrations of the chlorinated hydrocarbons in the headspace of the test bottles were monitored by drawing $5 \mu \mathrm{l}$ of gas phase and $10 \mu \mathrm{l}$ gas in the headspace of the internal standard (1-chloro-2-bromo-propane) into a $25 \mu 1$ gas-tight syringe (Hamilton, Cat. No. 1702RN) and injecting sample into a gas chromatograph (model 5890A, Hewlett-Packard, Avondale, $\mathrm{Pa}$ ) equipped with an electron capture detector (ECD). An Ultra-1 capillary column (methyl silicon column, $25 \mathrm{~m} \times 0.32 \mathrm{~mm} \times 0.52 \mu \mathrm{m}$, Supelco Inc., Bellefonte, $\mathrm{Pa}$ ) was used for separating the chlorinated compounds. The column temperature was kept isothermally at $35^{\circ} \mathrm{C}$ and with the carrier gas $\left(\mathrm{N}_{2}\right)$ flow rate at $1.76 \mathrm{ml} / \mathrm{min}$ (linear velocity $36.5 \mathrm{~cm} / \mathrm{s}$ ). The analytical error was controlled within $5 \%$. The error was determined by calculating the relative standard deviation (RSD) of the peak area of the internal standard $(n=26-30)$ and frequently checked during the analysis. The detection limits, corresponding to the concentrations in liquid culture, were $0.21 \mu \mathrm{g} / 1$ for TCA, $0.10 \mu \mathrm{g} / 1$ for CT and $0.60 \mu \mathrm{g} / 1$ for CF.

The test bottles were opened after headspace analyses, and $\mathrm{pH}$, oxidation-reduction potential (ORP), and total organic carbon (TOC) in the liquid phases were analyzed. ORP and $\mathrm{pH}$ were determined with an Orion EA920 expandable ion analyzer (Orion Research Inc., Boston, Mass.) by using an Orion gel-filled combination $\mathrm{pH}$ electrode for $\mathrm{pH}$ measurements and an Orion model 97-78-00 $\mathrm{Pt}$ redox electrode for ORP measurement. Total organic carbon (TOC) and volatile suspended solid (VSS) were analyzed to evaluate the changes of substrate and microbial concentrations in the liquid phases of serum bottles. VSS was measured according to Standard Methods (1985) with minor modification. After filtering of the entire contents of the microcosm, the residue on the filter was rinsed with $0.1 \mathrm{~N} \mathrm{HCl}$ to eliminate the interference of inorganic carbon, dried at $105^{\circ} \mathrm{C}$ and then ignited to a constant weight in a muffle furnace at a temperature of $550 \pm 50^{\circ} \mathrm{C}$ for 15-20 min. TOC concentrations in the filtrates were obtained by a TOC analyzer (Model 700, O.I. Corporation, Tex.) after filtration.

\section{RESULTS}

\section{Biotransformation of carbon tetrachloride (CT)}

The biotransformation of $100 \mu \mathrm{g} / \mathrm{l}$ of CT with the amendment of $0-30 \mathrm{mg} / \mathrm{l}$ of acetic acid as the auxiliary substrate is illustrated in Fig. 1. The rate of removal of $\mathrm{CT}$ was increased progressively with the increase of the substrate concentration. As shown in Fig. 1, the culture with $5 \mathrm{mg} / \mathrm{l}$ of acetic acid exhibited $99.9 \%$ removal of $\mathrm{CT}$ in $15 \mathrm{~d}$, whereas the same removal was observed in $6 \mathrm{~d}$ when substrate concentration was increased to $30 \mathrm{mg} / \mathrm{l}$. The culture bottle with no addition of auxiliary substrate also exhibited $99.9 \%$ of the original CT removal in $32 \mathrm{~d}$. This may be due to the presence of trace organic growth factors, such as biotin, vitamin $B_{12}$, thiamin, and nicotinic acid, in the original medium and carbon compounds from lyzed cells. The TOC concentration in the liquid phase of the bottles without addition of substrate was found decreased from $4.5 \mathrm{mg} / 1$ $(4.0-5.1 \mathrm{mg} / \mathrm{l})$ at day 14 to $2.2 \mathrm{mg} / \mathrm{l}(2.1-2.4 \mathrm{mg} / \mathrm{l})$ at day 35 which supported this view. As CT concentration increases to 500 and $1000 \mu \mathrm{g} / \mathrm{l}$ (Figs 2 and 3), similar degradation pattern was observed, however, longer times were required to reach the $99.9 \%$ removal of the CT, depending on the amount of the substrate added.

The amount of chloroform (CF) produced is progressively correlated with the concentration of CT (Fig. 4). However, lower fraction of the CT transformation (15-20\%) was observed as CF. Galli and McCarty (1989) depicted that CT could be dehalogenated by Clostridium sp. and led to the intermedi- 


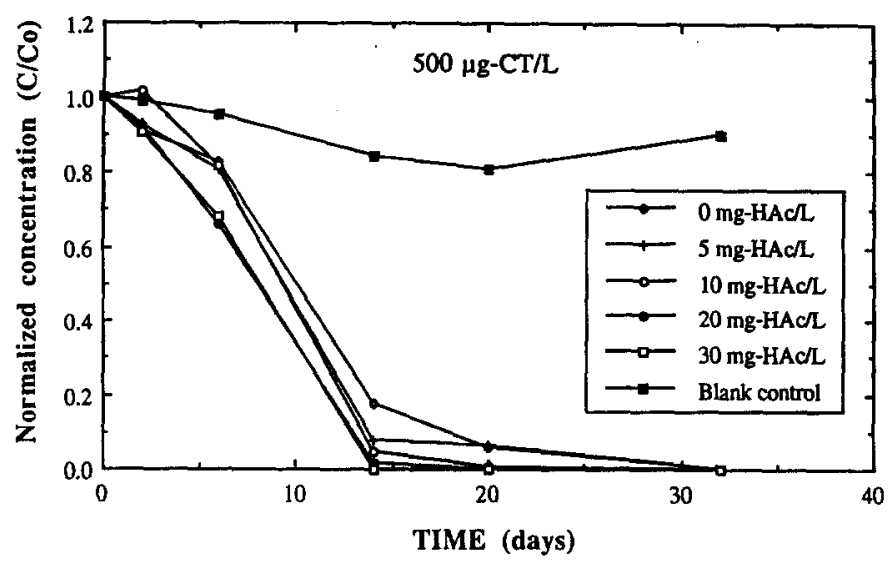

Fig. 2. Biotransformation of $500 \mu \mathrm{g} / 1$ of carbon tetrachloride (CT) with the supplement of auxiliary substrate (acetic acid) ranged from 0 to $30 \mathrm{mg} / 1$.

ated CF, which was further transformed to dichloromethane $(8 \%)$ and unidentified products. Criddle et al. (1990) found that the composition of the product of CT transformation was dependent on the condition of the electron acceptor in the media. A great fraction of CT was converted to CF and cell-bound fraction under glucose-fermenting conditions, whereas $\mathrm{CO}_{2}, \mathrm{CF}$ and nonvolatiles were predominant under fumarate-respiring conditions. Parallel pathways have also been presented for the degradation of CT under anaerobic condition. These imply that CF could be an intermediated or other parallel pathways occur in the microbial system. However, available data are insufficient to confirm whether the lower fraction was due to changing pathways or greater CF transformation.

\section{Biotransformation of 1,1,1-trichloroethane (TCA)}

Result in Fig. 5 shows that the biotransformation of $100 \mu \mathrm{g} / 1$ of TCA is directly related to the concentrations of the auxiliary substrate and TCA. With the addition of the substrate, removal of TCA increased from $43 \%$ at the substrate concentration of $5 \mathrm{mg} / \mathrm{l}$ to $79 \%$ at the substrate concentration of $30 \mathrm{mg} / 1$ in $85 \mathrm{~d}$. The pattern of the degradation of TCA in bottles without acetic acid was consistent with those in blank controls, suggesting that the anaerobic microorganisms had no capability for dechlorination of TCA when there was no adequate energy and reducing sources in the environment. The increase of TCA concentration resulted in the decrease of the removal ratio. With the increasing of TCA concentration to $500 \mu \mathrm{g} / 1$, removal of only $25-48 \%$ of the original TCA was observed (Fig. 6), furthermore removal of $27-38 \%$ was observed in $85 \mathrm{~d}$ when bottles were spiked with $1000 \mu \mathrm{g} / 1$ TCA (Fig. 7).

Long acclimation was observed for TCA biotransformation (Table 3). The acclimation denotes a length of time during the initial exposure of microorganisms to a chemical in which the transformation rates of the chemical are too slow to be measurable and is determined as the time required to detect at least $10 \%$ loss of the original TCA concentration relative to the blank control (Gibson and Suflita,

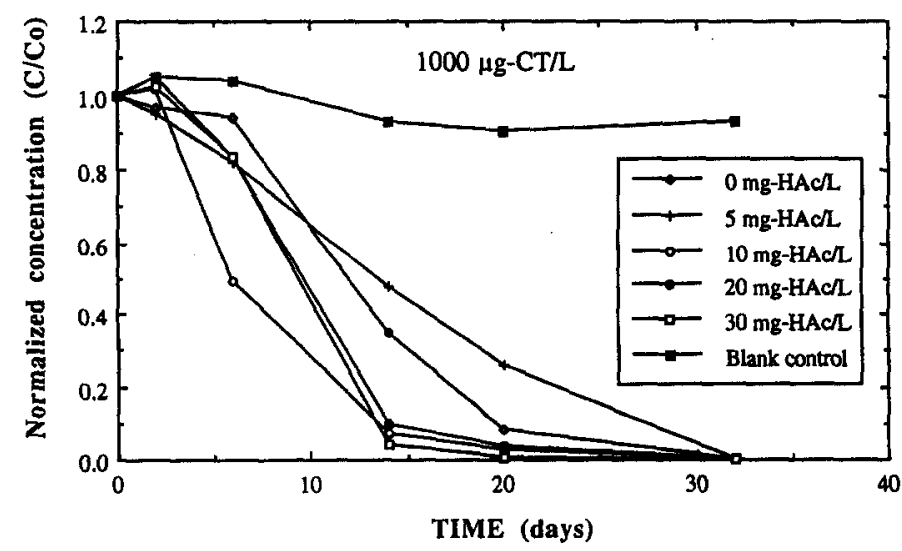

Fig. 3. Biotransformation of $1000 \mu \mathrm{g} / 1$ of carbon tetrachloride (CT) with the supplement of auxiliary substrate (acetic acid) ranged from 0 to $30 \mathrm{mg} / \mathrm{l}$. 


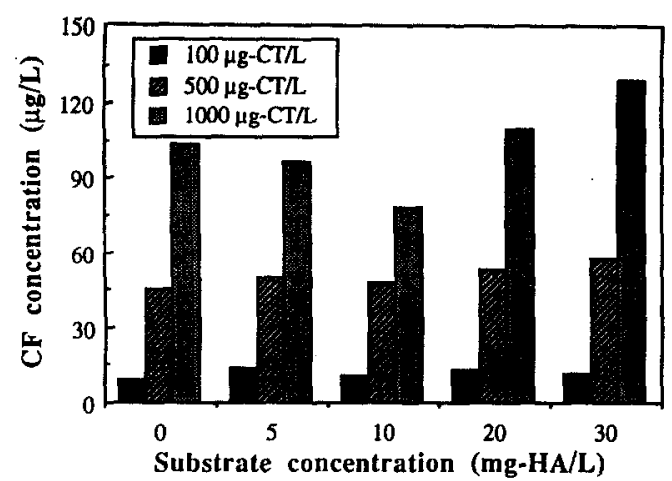

Fig. 4. The amount of chloroform (CF) produced from CT by the reductive dechlorination reaction.

1990). At TCA concentration of $100 \mu \mathrm{g} / \mathrm{l}$, the acclimation was inversely correlated with the concentration of auxiliary substrate and was varied from $32 \mathrm{~d}$ at the substrate concentration of $5 \mathrm{mg} / 1$ to $2 \mathrm{~d}$ at the substrate concentration of $30 \mathrm{mg} / \mathrm{l}$. Longer acclimation, 20 and $32 \mathrm{~d}$, respectively, were required for the TCA concentrations of 500 and $1000 \mu \mathrm{g} / \mathrm{l}$. The microcosm without the auxiliary substrate required longer acclimation than those with auxiliary substrates added, demonstrating that high concentration of auxiliary substrate could effectively increase the biotransformation efficiency of TCA.

\section{Abiotic transformation}

In blank controls, CT concentration decreased as well with slower rates than the inoculated treatments and significant amount of chloroform was produced over the experimental course of $85 \mathrm{~d}$. Galli and McCarty (1989) also found that the CT concentration decreased significantly in the sterile controls when Clostridium sp. was used to transform CT, TCA, and CF. The abiotic transformations of chlorinated aliphatic compounds have been shown to occur in highly reduced aqueous solutions containing transition-metal coenzymes (Klecka and Gonsior, 1984; Gantzer and Wackett, 1991; Assaf-Anid et al., 1994). To verify this hypothesis, abiotic transformation experiments with different compositions of anaerobic medium were performed. Table 4 shows the abiotic transformation of $100 \mu \mathrm{g} / \mathrm{l} \mathrm{CT}$ and TCA in F, S, and FS media. About $84 \%$ of the original CT was depleted in the solution containing ferrous ion alone ( $F$ medium) in $33 \mathrm{~d}$, whereas no reduction of $\mathrm{CT}$ was observed in the other two conditions ( $S$ and FS media). For TCA, no dechlorination occurred in all solutions over the experimental period of $33 \mathrm{~d}$. These results show that abiotic transformation of CT is possible when the anaerobic medium contains ferrous ions. However, sulfide and bound $\mathrm{Fe}^{2+}$ could not catalyze the reaction of dechlorination without the mediation of microorganisms.

\section{Biotransformation rate constants}

The rate of biotransformation of chlorinated compounds can be quantified with a Monod equation according to

$$
\frac{\mathrm{d}[R-\mathrm{C}]}{\mathrm{d} t}=-\frac{k_{\mathrm{m}}[X][R-\mathrm{Cl}]}{K_{\mathrm{sc}}+[R-\mathrm{Cl}]}
$$

where $[R-\mathrm{Cl}]$ is the concentration of the chlorinated compound, $[X]$ is the concentration of biomass, $k_{\mathrm{m}}$ is the maximum utilization rate coefficient for the chlorinated compound, and $K_{\mathrm{sc}}$ is the half-saturation concentration of the chlorinated compound. The Monod relationship here serves as a fundamental equation for modeling the biotransformation of chlorinated hydrocarbons.

For the situation that there is only trace amount of chlorinated compounds in the system, the Monod equation can be reduced to a second-order kinetic reaction by assuming that $[R-C l]$ is much lower than $K_{\mathrm{s}}$. The second-order reaction rate constant,

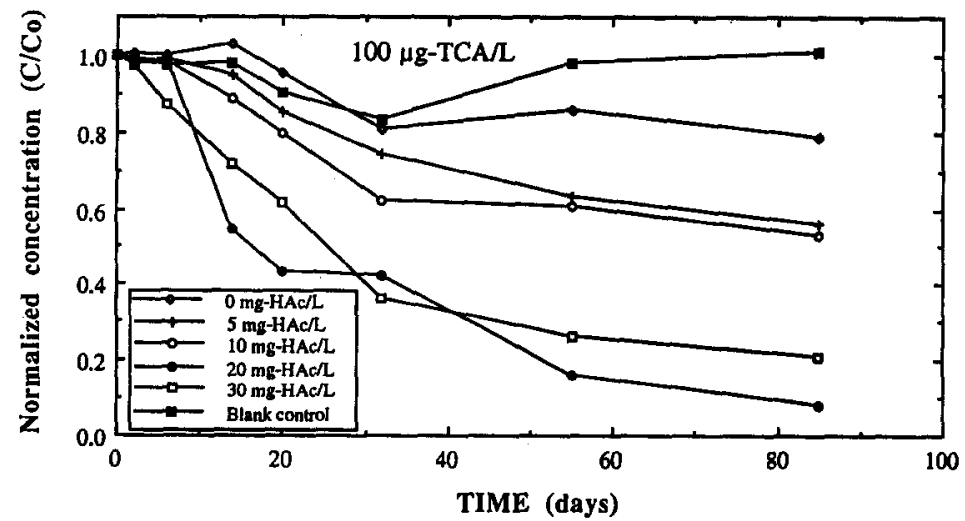

Fig. 5. Biotransformation of $100 \mu \mathrm{g} / 1$ of 1,1,1-trichloroethane (TCA) with the supplement of auxiliary substrate (acetic acid) ranged from 0 to $30 \mathrm{mg} / 1$. 


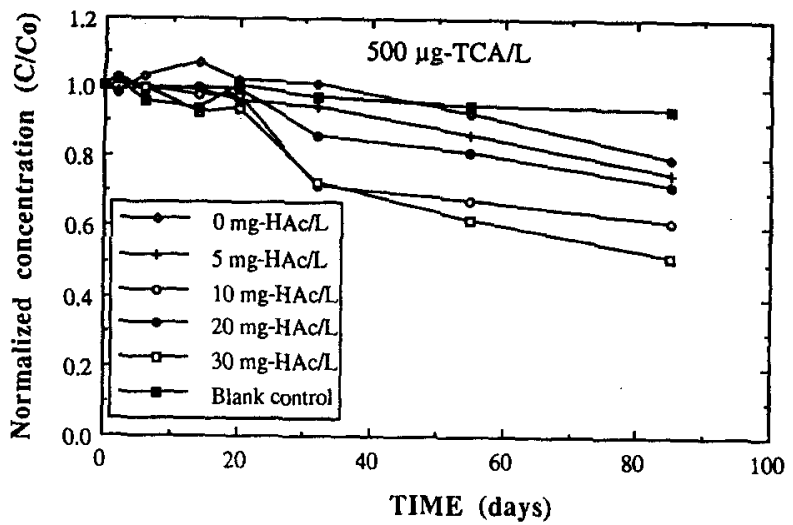

Fig. 6. Biotransformation of $500 \mu \mathrm{g} / \mathrm{l}$ of $1,1,1$-trichloroethane (TCA) with the supplement of auxiliary substrate (acetic acid) ranged from 0 to $30 \mathrm{mg} / 1$.

$k\left(=k_{\mathrm{m}} / K_{\mathrm{sc}}\right)$, in the following equation is the only parameter to be estimated

$$
\frac{\mathrm{d}[R-\mathrm{Cl}]}{\mathrm{d} t}=-k[X][R-\mathrm{Cl}] .
$$

Thus, the rates of the biotransformations of TCA and $\mathrm{CT}$ are related to the microbial populations and the concentrations of the chlorinated xenobiotics. The microbial populations determined by VSS concentration in bottles were essentially constant [109.2 $\pm 13.1 \mathrm{mg}$-VSS/l $(n=28)]$ over the experimental period of $85 \mathrm{~d}$, suggesting that cell growth was not significant in the studied systems. Thus, the secondorder rate coefficient $(k)$ could be estimated by fitting experimental results in which the rates of sterile controls were substracted. As shown in Fig. 8, rate constants of $\mathrm{CT}$ at a concentration of $100 \mu \mathrm{g} / \mathrm{l}$ were increased consistently with the increase of the substrate concentration and ranged from $0.00161 / \mathrm{mg}$. VSS/d at the substrate concentration of $5 \mathrm{mg} / 1$ to $0.00331 / \mathrm{mg}-\mathrm{VSS} / \mathrm{d}$ at the substrate concentration of $30 \mathrm{mg} / \mathrm{l}$. At concentrations of 500 and $1000 \mu \mathrm{g} / \mathrm{l}$, rate constants of CT were slightly lower and increased gradually with additional concentration of auxiliary substrate and ranged between 0.0006 and $0.00171 / \mathrm{mg}-\mathrm{VSS} / \mathrm{d}$. Surprisingly, the rate constants of the microcosms without auxiliary substrate also had approximately the same ranges as those with low concentrations of auxiliary substrate added $(0.0008$ to $0.0012 \mathrm{l} / \mathrm{mg}-\mathrm{VSS} / \mathrm{d}$ ). It suggests that the biotransformation of CT may be fueled by very low concentration of carbon sources from the inoculum.

TCA had lower rate constants than those of CT (Fig. 9). The effect of the auxiliary substrate concentration on the degradation of TCA were more obvious than that on CT. The rate coefficients of the microcosms without auxiliary substrate and with $1000 \mu \mathrm{g} / 1 \mathrm{TCA}$ were not calculated for their extraordinary long adaptation times (32-56 d). The second-order rate constants of TCA increased from $6.1 \times 10^{-5}$ to $2.97 \times 10^{-4} \mathrm{l} / \mathrm{mg}$-VSS $/ \mathrm{d}$ and $2.75 \times 10^{-5}$ to $7.16 \times 10^{-5}$ for TCA concentrations of 100 and $500 \mu \mathrm{g} / 1$, respectively, and gradually increased with the increasing substrate concentrations. These rate coefficients correspond to half lives of 23-193 d for TCA and less than $15 \mathrm{~d}$ for CT, respectively, by assuming a constant microbial concentration over the experimental period. These data are

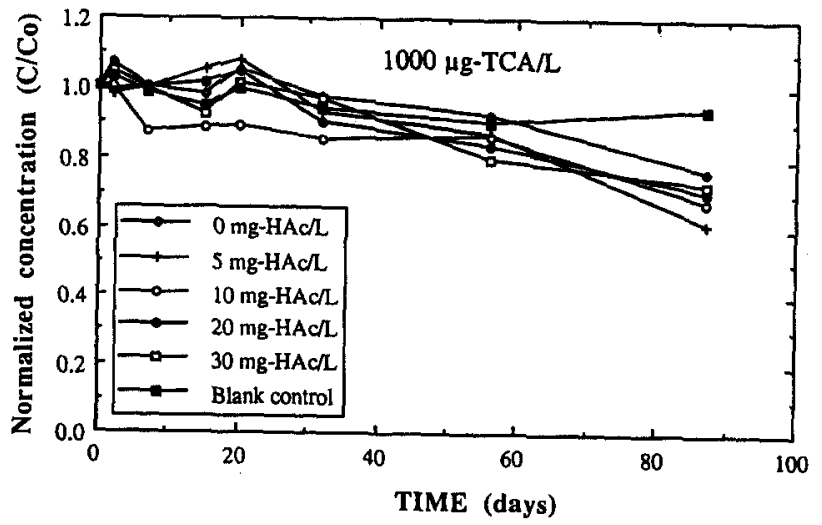

Fig. 7. Biotransformation of $1000 \mu \mathrm{g} / \mathrm{l}$ of $1,1,1-$ trichloroethane (TCA) with the supplement of auxiliary substrate (acetic acid) ranged from 0 to $30 \mathrm{mg} / \mathrm{l}$. 
Table 3. Acclimation of 1,1,1-trichloroethane (TCA) and carbon tetrachloride (CT) with different concentrations of supplemental substrate (acetic acid). Concentrations added in microcosms were 100,500 , and $1000 \mu \mathrm{g} / \mathrm{l}$ for chlorinated hydrocarbons and $0,5,10$, 20 , and $30 \mathrm{mg} / 1$ for supplemental substrate, respectively

\begin{tabular}{lccc}
\hline $\begin{array}{l}\text { Chlorinated } \\
\text { hydrocarbon } \\
\text { concentration } \\
(\mu \mathrm{g} / \mathrm{l})\end{array}$ & $\begin{array}{c}\text { Added } \\
\text { substrate } \\
\text { concentration } \\
(\mathrm{mg} / \mathrm{l})\end{array}$ & \multicolumn{2}{c}{ Acclimation $(\mathrm{d})^{\mathbf{a}}$} \\
\cline { 2 - 4 } 100 & 0 & $\mathrm{CT}$ & TCA \\
& 5 & 2 & 56 \\
& 10 & 2 & 32 \\
& 20 & $<2$ & 15 \\
500 & 30 & $<1$ & 2 \\
& 0 & 2 & 55 \\
& 5 & 2 & 32 \\
& 10 & 2 & 20 \\
1000 & 20 & $<1$ & 20 \\
& 30 & $<1$ & 20 \\
& 0 & 6 & 56 \\
& 5 & 2 & 32 \\
& 10 & 2 & 20 \\
& 20 & 2 & 32 \\
& 30 & 2 & 32 \\
\hline
\end{tabular}

${ }^{a}$ Acclimation were estimated based on the time required to detect at least $10 \%$ loss of the original concentration relative to the blank control.

in good agreement with the reported results which are $16-230 \mathrm{~d}$ for TCA and less than $80 \mathrm{~d}$ for CT, respectively (Roberts et al., 1982; Wood et al., 1985; Bouwer and Wright, 1988).

\section{DISCUSSION}

During the experimental course, different biotransformabilities of CT and TCA were observed when culture bottles amended with different concentrations of auxiliary substrate or different concentrations of chlorinated compound. CT has the higher biotransformation rate and is less susceptible to the change of the substrate concentration relative to TCA. The difference of the redox potential $\left(E_{\mathrm{h}}\right)$ between these two chlorinated compounds can be used to explain this discrepancy (Vogel et al., 1987). Compounds with high redox potentials, like CT, can draw significant amount of electrons from electron donors. However, these compounds with low redox potentials, like TCA, will not get enough electron activity and higher concentration of substrate is needed for the reductive dechlorination. Gantzer and Wackett (1991) also demonstrated a good correlation between $\log _{10} K_{1}$, the pseudo-first-order rate constant, and the standard reduction potential of the chlorinate hydrocarbon by using the bacterial transition-metal vitamin $\mathbf{B}_{12}(\mathrm{Co})$, coenzyme $F_{430}(\mathrm{Ni})$, and hematin $(\mathrm{Fe})$ as catalysts for the reductive dechlorination of chlorinated ethylenes. It reveals that compound with higher reduction potential has higher dechlorination rate under reducing environment.

Adequate electron activity in the system is considered to be necessary for the onset of the dechlorination, and one of the reactions involved in the electron transfer pathway will be the rate-limiting reaction (Vogel et al., 1987; Distefano et al., 1991; Kastner, 1991). By taking the electron activity into account, the equation of the rate of transformation [equation (2)] becomes

$$
\frac{\mathrm{d}[R-\mathrm{Cl}]}{\mathrm{d} t}=-k_{\mathrm{r}}[X][R-\mathrm{Cl}][e]
$$

where the activity of electrons, $[e]$, is a function of the concentrations of the auxiliary substrate, the electron acceptors and the microbial organisms. It is assumed that electrons are produced from the utilizations of the auxiliary substrate and organic biomass released from dying cells. The rate of the production of electrons by bacteria is assumed to be parallel to the substrate utilization rate, therefore can be formulated as

$$
(e)_{\mathrm{p}}=Y_{\mathrm{es}} \frac{\mu_{\mathrm{m}}[X][S]}{K_{\mathrm{s}}+[S]}=\frac{k_{\mathrm{em}}[X][S]}{K_{\mathrm{s}}+[S]}
$$

where $(e)_{\mathrm{p}}$ is the electron formation rate, $\mu_{\mathrm{m}}$ is the maximum substrate utilization rate $(1 / \mathrm{d}), K_{\mathrm{s}}$ is the half-saturation concentration of the auxiliary substrate $(\mathrm{mg} / \mathrm{l}), Y_{\mathrm{es}}$ is yield coefficient of electron per unit mass of substrate $(=\Delta e / \Delta S)$, and $k_{\mathrm{em}}$ is the maximum generation rate of electrons. In addition to chlorinated hydrocarbons, a variety of electroncarrying metabolites existing in the microbial cell also serve as scavengers for electrons. The consumption rate of electron can thus be written as

$$
(e)_{\mathrm{c}}=\Sigma k_{i}[e][X][A]_{i}+k_{\mathrm{r}}[e][X][R-\mathrm{Cl}]
$$

where $k_{i}$ is the consumption rate constant of the ith electron acceptor existing in the environment, $k_{\mathrm{r}}$ is the consumption rate constant of the chlorinated

\begin{tabular}{|c|c|c|c|c|c|c|c|c|}
\hline \multirow{2}{*}{$\begin{array}{l}\text { Time } \\
\text { (d) }\end{array}$} & \multicolumn{4}{|c|}{ Remaining fraction of $\mathrm{CT}(\mathrm{C} / \mathrm{Co})^{a}$} & \multicolumn{4}{|c|}{ Remaining fraction of $\mathrm{TCA}(\mathrm{C} / \mathrm{Co})$} \\
\hline & $F$ & $S$ & FS & BL & $F$ & $\mathrm{~S}$ & FS & BL \\
\hline 0 & 1.0 & 1.0 & 1.0 & 1.0 & 1.0 & 1.0 & 1.0 & 1.0 \\
\hline 2 & 0.608 & 1.047 & 1.147 & 1.051 & 1.091 & 1.091 & 1.212 & 1.056 \\
\hline 10 & $-^{b}$ & 1.094 & 1.115 & 1.102 & — & 0.941 & 1.110 & 1.123 \\
\hline 23 & 0.032 & 0.745 & 1.055 & 0.963 & 1.095 & 0.872 & 1.099 & 1.004 \\
\hline 33 & 0.163 & 0.865 & 0.870 & 0.863 & 1.115 & 1.203 & 1.033 & 1.003 \\
\hline
\end{tabular}

Table 4. Abiotic transformations of carbon tetrachloride (CT) and 1,1,1-trichloroethane (TCA) in different compositions of solutions

" $F$ medium: solution containing ferrous ion $\left(\mathrm{Fe}^{2+}\right)$ alone.

$S$ medium: solution containing sulfide ion $\left(\mathrm{S}^{2-}\right)$ alone.

FS medium: solution containing ferrous and sulfide ions

BL medium: blank control.

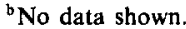




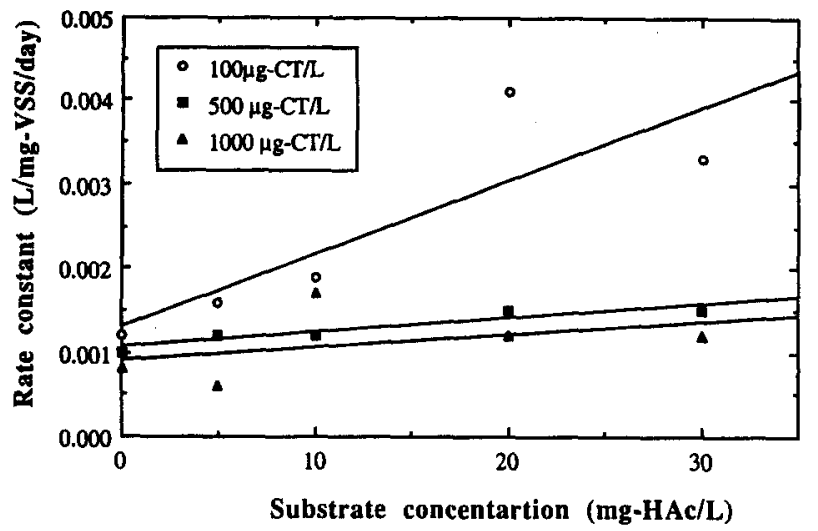

Fig. 8. Second-order rate constants of carbon tetrachloride (CT) with the amendment of substrate concentration ranged from 0 to $30 \mathrm{mg} / \mathrm{l}$.

hydrocarbon, and $[A]_{i}$ represent the concentration of the ith electron acceptor existing in the system except chlorinated hydrocarbons. Assuming that $[A]_{i s}$ are abundant and are all constant in the defined environment, from equations (5) and (6), the net formation rate of electron can be written as

$$
\begin{aligned}
\frac{\mathrm{d}[e]}{\mathrm{d} t} & =(e)_{\mathrm{p}}-(e)_{\mathrm{c}} \\
& =\frac{k_{\mathrm{em}}[X][S]}{K_{\mathrm{s}}+[S]}-k_{\mathrm{a}}[X][e]-k_{\mathrm{r}}[e][X][R-\mathrm{Cl}]
\end{aligned}
$$

where $k_{\mathrm{a}}\left(=\Sigma k_{\mathrm{i}}[A]_{i}\right)$ is the effective consumption rate constant due to all other electron acceptors. At steady state, equation (7) can be written as

$$
\begin{aligned}
{[e]=} & \frac{k_{\mathrm{em}}[X][S]}{\left(k_{\mathrm{a}}[X]+k_{\mathrm{r}}[X][R-\mathrm{Cl}]\right)\left(K_{\mathrm{s}}+[S]\right)} \\
& =\frac{k_{\mathrm{em}}[S]}{\left(k_{\mathrm{a}}+k_{\mathrm{r}}[R-\mathrm{Cl}]\right)\left(K_{\mathrm{s}}+[S]\right)} .
\end{aligned}
$$

From equations (3) and (7), it is predictable that higher concentration of supplemental substrate offers more carbon and electron sources for microorganisms to produce high concentrations of electrons and mediate the reactions of dechlorination more readily. Also, a high enough concentration of chlorinated compound $([R-\mathrm{Cl}])$ could significantly reduce the electron activity, $[e]$, and result in a lower rate of biotransformtion if the substrate concentration is low. If there is only trace amount of chlorinated compounds present in the environment and all of the environmental factors such as the concentrations of electron acceptors, redox potential and the concentration of microbial organisms remain constant in short intervals, the concentration of available free electrons will only be controlled by the primary substrate concentration. That is, from equation (7)

$$
[e]=\text { constant } \times[S]
$$

substituting $[e]$ into equation (3), we will find that biotransformation rate is a function of the substrate concentration during a short time interval.

Sensitivity analyses showed that the maximum substrate utilization rate $\left(\mu_{\mathrm{m}}\right)$, the rate coefficient $\left(k_{\mathrm{r}}\right)$, the concentration of the chlorinated hydrocarbon,

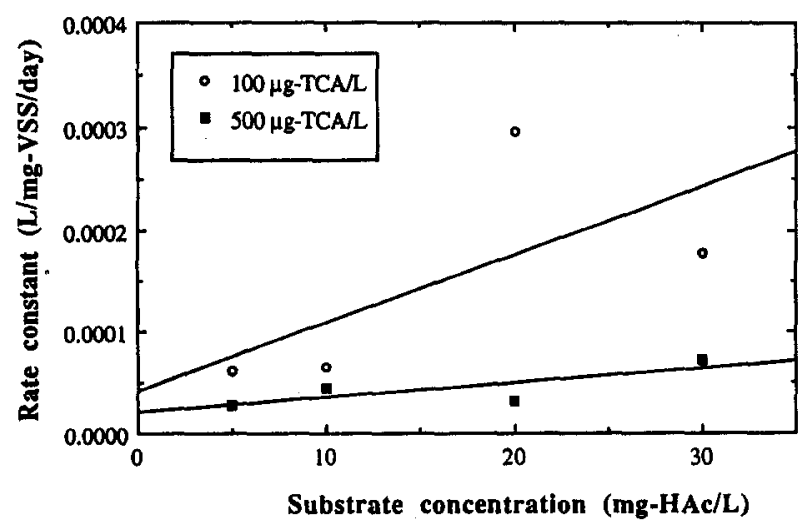

Fig. 9. Second-order rate constants of 1,1,1-trichloroethane (TCA) with the amendment of substrate concentration ranged from 0 to $30 \mathrm{mg} / \mathrm{l}$. 


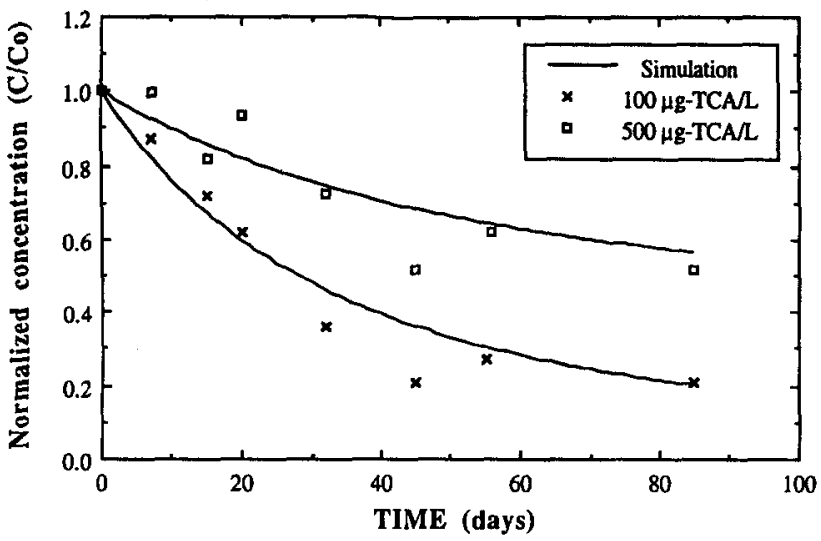

Fig. 10. Comparisons of simulation and experimental results of 1,1,1-trichloroethane (TCA) at concentrations of $100 \mu \mathrm{g} / \mathrm{l}$ and $500 \mu \mathrm{g} / \mathrm{l}$ when the auxiliary substrate concentration was $30 \mathrm{mg} / \mathrm{l}$.

the concentration of the microbial organisms and the auxiliary substrate are the major factors controlling the rate of biotransformation of the chlorinated hydrocarbon, and the electron activity is the most important parameter affecting the biotransformation rate of chlorinated compounds. Galli and McCarty (1989) examined the effects of high concentration of TCA on the biotransformation of TCA by Clostridium sp. strain TCAIIB, and depicted that the decreasing of the activity of the nongrowing cells to transform xenobiotics in the absence of growth substrate was due to an exponential decrease in the activity of biomass over time. A modified Monod equation was also proposed to describe the kinetics of TCA. In the present model, the role of the available electron activity is emphasized rather than the activity of biomass. Simulations of the reductive dechlorination of TCA at concentrations of 100 and $500 \mu \mathrm{g} / \mathrm{l}$ with $30 \mathrm{mg} / \mathrm{l}$ of auxiliary substrate are illustrated in Fig. 10. These results of simulation are well consistent with the experimental data, showing that electron activity is an important controlling factor for the dechlorination of chlorinated hydrocarbons.

In this study, VSS was chosen to represent the microbial mass and remained essentially unchanged. Although only a small part of VSS is active, it is an easily measurable parameter for estimating the microbial mass and rate coefficients. Galli and McCarty (1989) used protein content to represent the microbial mass and depicted that TCA could be depleted with the concentration of the anaerobic consortia remaining essentially constant. Kastner (1991) pointed out that the number of cells in dechlorination cultures was decreasing during PCE dechlorination. Furthermore, Fathepure and Boyd (1988) proposed that electrons transferred during methanogenesis were diverted to PCE by a reduced electron carrier involved in methane formation. DiStefano et al. (1991) also demonstrated an electron balance during PCE dechlorination. The reductive dechlorination process requires an electron donor provided by a transfer of electrons from an auxiliary substrate to chlorinated hydrocarbons through a microbial system. Thus, the reductive dechlorination of chlorinated hydrocarbons is proceeded by competing electrons with electron-carrying metabolites existing in the microbial system rather than coupling with microbial growth.

\section{CONCLUSIONS}

The results presented in this paper indicate that the low concentration of the auxiliary substrate can support the microbial dechlorination capability and, thus, accelerate the biotransformation rate of CT and TCA. Better biotransformation efficiency is evident when the environment received high concentration of auxiliary substrate. The added auxiliary substrate serves as an electron donor coupled with chlorinated hydrocarbons as terminal electron acceptors. Thus, higher concentration of auxiliary substrate provides higher intensity of available electrons for anaerobic microbial communities to facilitate the dechlorination and causes a corresponding increase of the biotransformation efficiency. It is also important to emphasize that the concentration of chlorinated hydrocarbon is an effective factor influencing the biotransformation efficiency. Model simulation infers that available electron activity produced by microorganisms by the utilization of substrate is essential for the decontamination of such heavily chlorinated compounds. These results could serve as good considerations for choosing the concentration of the substrate supplemented in the remediation of the contaminated groundwaters. Further work concerning the fate of the chlorinated hydrocarbons under the supplement of different concentrations of substrate will be conducive to elucidate the role of the supplemental substrate on the dechlorination of chlorinated hydrocarbons. 
Acknowledgements - The authors would like to express their thanks to National Science Council, R.O.C. for financial support under grant No. NSC 79-0410-E002-03.

\section{REFERENCES}

Assaf-Anid N., Hayes K. F. and Vogel T. M. (1994) Reductive dechlorination of carbon tetrachloride by cobalamin (II) in the presence of dithiothreitol: mechanistic study, effect of redox and pH. Environ. Sci. Technol. 28, 246-252.

Bouwer E. J. and Wright J. P. (1988) Transformations of trace halogenated aliphatics in anoxic biofilm column. J. contam. Hydrol. 2, 155-169.

Criddle C. S., DeWitt J. T. and McCarty P. L. (1990) Reductive dehalogenation of carbon tetrachloride by Escherichia coli K-12. Appl. environ. Microbiol. 56, 3247-3254.

DiStefano T. D., Gossett J. M. and Zinder S. H. (1991) Reductive dechlorination of high concentrations of tetrachloroethene to ethene by an anaerobic enrichment culture in the absence of methanogenesis. Appl. environ. Microbiol. 57, 2287-2292.

Doong R. A. and Wu S. C. (1995) Enhanced degradation of carbon tetrachloride by the supplement of substrate and mineral ions under anaerobic condition. Wat. environ. Res. 67, 276-281.

Enzien N. V., Picardal F., Hazen T. C., Arnold R. G. and Fliermans C. B. (1994) Reductive dechlorination of trichloroethylene and tetrachloroethylene under aerobic conditions in a sediment column. Appl. environ. Microbiol. 60, 2200-2204.

Fathepure B. Z. and Boyd S. A. (1988) Dependence of tetrachloroethylene dechlorination on methanogenic substrate consumption by Methanosarcina sp. strain DCM. Appl. environ. Microbiol. 54, 2976-2980.

Federal Register (1989) National primary and secondary drinking water regulations; proposed rule. Fed. Regist. 54, 22062-22160

Galli R. and McCarty P. L. (1989) Kinetics of biotransformation of 1,1,1-trichloroethane by Clostridium sp. strain TCAIIB. Appl. environ. Microbiol. 55, 845-851.

Gantzer C. J. and Wackett L. P. (1991) Reductive dechlorination catalyzed by bacteria transition-metal coenzymes. Environ. Sci. Technol. 25, 715-722.

Gibson S. A. and Sewell G. W. (1992) Simulation of reductive dechlorination of tetrachloroethene in anaerobic aquifer microcosms by addition of short-chain organic acids and alcohols. Appl. environ. Microbiol. 58, 1392.
Gibson S. A. and Suflita J. M. (1990) Anaerobic biodegradation of 2,4,5-Trichlorophenoxyacetic acid in samples from a methanogenic aquifer: simulation by short-chain organic acids and alcohols. Appl. environ. Microbiol. 56, 1825-1832.

Hopkins G. D., Semprini L. and McCarty P. L. (1993) Microcosms and in situ field studies of enhanced biotransformation of trichloroethylene by phenol-utilizing microorganisms. Appl. environ. Microbiol. 59, 2277-2285.

Kastner M. (1991) Reductive dechlorination of tri- and tetrachloroethylenes depend on transition from aerobic to anaerobic conditions. Appl. environ. Microbiol. 57, 2039-2046.

Klecka G. M. and Gonsior S. J. (1984) Reductive dechlorination of chlorinated methanes and ethanes by reduced iron(II) porphyrins. Chemosphere 13, 391-402.

Kuhn E. P., Townsend G. T. and Suflita J. M. (1990) Effect of sulfate and organic carbon supplements on the reductive dehalogenation of chloroanilines in anaerobic aquifer slurries. Appl. environ. Microbiol. 56, 2630-2637.

Nies L. and Vogel T. M. (1990) Effects of organic substrates on dechlorination of Aroclor 1242 in anaerobic sediments. Appl. environ. Microbiol. 56, 2612-2617.

Roberts P. V., Schreiner J. and Hopkins G. D. (1982) Field study of organic water quality changes during groundwater recharge in the Palo Alto Baylands. Wat, Res. 16, 1025-1035.

Semprini L. and McCarty P. L. (1992) Comparison between model simulations and field results for in-situ biorestoration of chlorinated aliphatics: part 2. cometabolic transformations. Ground Wat. 30, 37-44.

Semprini L., Hopkins G. D., McCarty P. L. and Roberts P. V. (1992) In-situ transformation of carbon tetrachloride and other halogenated compounds resulting from biostimulation under anoxic conditions. Environ. Sci. Technol. 26, 2454-2461.

Tandol V., DiStefano T. D., Bowser P. A., Gossett J. M. and Zinder S. H. (1994) Reductive dehalogenation of chlorinated ethenes and halogenated ethanes by a highrate anaerobic enrichment culture Environ. Sci. Technol. 28, 973-979.

Thomas J. M. and Ward C. H. (1989) In situ biorestoration of organic contaminants in the subsurface. Environ. Sci. Technol. 23, 760-766.

Vogel T. M., Criddle C. S. and McCarty P. L. (1987) Transformations of halogenated aliphatic compounds. Environ. Sci. Technol. 21, 722-736.

Wood, P. R., Lang R. F. and Payan I. L. (1985) Anaerobic transformation, transport, and removal of volatile chlorinated organics in groundwater, p. 493-511. In Ground Water Quality (Edited by Ward C. H., Giger W. and McCarty P. L.). Wiley, New York. 